\title{
The Role of Management in Open Data Initiatives in Local Governments: Opening the Organizational Black Box
}

\author{
Mila Gasco-Hernandez \& J. Ramon Gil-Garcia
}

Center for Technology in Government \& Rockefeller College of Public Affairs and Policy, University at Albany, State University of New York, mgasco@ctg.albany.edu \& jgil-garcia@albany.edu

\begin{abstract}
Previous studies have infrequently addressed the dynamic interactions among social, technical, and organizational variables in open government data initiatives. In addition, organization level models have neglected to explain the role of management in decision-making processes about technology and data. This article contributes to addressing this gap in the literature by analyzing the complex relationships between open government data characteristics and the organizations and institutions in which they are embedded. We systematically compare the open data inception and implementation processes, as well as their main results, in three Spanish local governments (Gava and Rubi in Catalonia and Gijon in Asturias) by using a model that combines the technology enactment framework with some specific constructs and relationships from the process model of computing change. Our resulting model is able to identify and explain the significant role of management in shaping and mediating different interactions, but also acknowledges the importance of organizational level variables and the context in which the open data initiative is taking place.
\end{abstract}

Keywords: Open data, role of management, organizational forms, institutional arrangements, environment, technology enactment framework, process model of computing change.

\section{Introduction}

There is agreement among scholars and practitioners that open government data (OGD) has defined the open government movement to a certain degree since it is a valuable example of how the main values of open government can materialize: opening the data shows transparency, while simultaneously offering opportunities for collaboration among different stakeholders (Susha et al., 2015; Veljkovic et al., 2014). Consequently, many studies have focused on open government data policies and initiatives around the world, both at the national and local levels. These works have mainly addressed the drivers, benefits, and barriers of opening data (Hossain et al., 2016; Veenstra \& Van den Broek, 2013). 
The literature refers to political leadership, institutional pressure, and technological development as some of the drivers of opening data. Huijboom and Van den Broek (2011), for example, find that political leaders develop the guidelines and infrastructure necessary to open data; the researchers then claim that inspiring examples from successful countries are the major driver of OGD movements. The most cited benefits from opening data are greater transparency, innovation, and economic growth (Zuiderwijk et al., 2014 a; 2014b; Janssen et al., 2012). Finally, the most important impediments include a closed organizational culture and a lack of organizational capabilities (Yang \& Wu, 2016; Wirtz et al., 2016; Wirtz et al., 2016; Chris, 2014; Zuiderwijk et al., 2012), legal and regulatory issues, particularly those related to privacy and security (Zuiderwijk \& Janssen, 2014; Janssen et al., 2012; Zuiderwijk et al., 2014b; Khayyat \& Bannister, 2015), technical challenges, ranging from the unavailability of a supporting infrastructure to the lack of standards (Conradie \& Choenni, 2014; Janssen et al., 2012; Lyon et al., 2015), skills and knowledge gaps among public managers and employees (Lyon et al., 2015; Zuiderwijk et al., 2014), and economic factors, which include resources that government agencies need to curate and publish the data (Chris, 2014; Barry \& Bannister, 2014).

Despite previous literature on the role of culture and organizational attributes in the implementation of OGD initiatives, there is scarce research on how OGD projects may induce change in the structure of public organizations to realize their full potential (Van Veentsra et al., 2010). Data-oriented measurements and OGD studies addressing impact (such as the works of, among others, Susha et al., 2015; Zuiderwijk \& Janssen, 2014; Sayogo et al., 2014; Veljovic et al., 2014; Parycek et al., 2014; Solar et al., 2012) have frequently overlooked the organizational transformation which may accompany the deployment of the technical infrastructure for open government data (Susha et al., 2015). The few works that have addressed this topic show that OGD policies have resulted in limited transformation of government. For example, Zuiderwijk and Janssen (2014) argue that current OGD efforts are largely driven by technology and that organizations are not consequently adapting to achieve the desired effects of opening data. Similarly, Janssen et al. (2012) find a gap between the potential and realized benefits of OGD because most public organizations only focus on publishing data instead of shifting from a closed to an open system of governance. The authors recognize that, in line with the predictions of institutional theory, OGD is usually reinforcing existing structures instead of changing them and incorporating these new developments into daily operations.

Not only has prior research largely neglected OGD-induced change, but also the dynamic interaction between social and organizational structures and open government data projects. This article contributes to address this gap in the literature on OGD by analyzing the bilateral relationship between OGD initiatives and the organizations and social structures in which they are embedded. In order to do so, we compare and contrast the OGD decision-making and implementation processes in three Spanish local governments: Gava and Rubi in Catalonia and Gijon in Asturias. These three governments have adopted an open government data approach that goes beyond the scope of what other local governments in the country have done. In particular, the goal of this research is to understand the interplay between social and organizational structures and open government data projects (including their inception, implementation, and results). Thus, two research question drive our study: (1) what are the results of opening government data?, and 
(2) how do different types of variables (organizational, institutional, environmental) affect open government data initiatives?

The remainder of this paper is organized as follows: in the next section, we introduce the theoretical lenses that have been applied to our case studies; the technology enactment framework and the process model of computing change. We are proposing that by adding elements from the process model of computing change, researchers can more clearly identify the role of management in open government data initiatives. Next, we explain the research design, based on a qualitative comparative case study approach. Subsequently, we present our results and analyze the interaction of organizational, institutional, and environmental factors in open data initiatives. Finally, we draw conclusions and point out recommendations for further research.

\section{The relationships between technology and organizational change}

“Technology affects society and government, but the causal arrows work in both directions. Technological change creates new challenges and opportunities for social and political organizations, but the response to those challenges depends on history, culture, institutions, and paths already taken or forgone" (Nye, 2002, p. 2). Several theories recognize the interplay between social structures and information technology; they have been classified as the "ensemble view" of technology (Orlikowski \& Iacono, 2001). This view argues that, in order to understand information technologies, it is necessary to analyze not only the technological artifacts, but also the social and technological aspects around those artifacts (Gil-Garcia, 2012).

We have used two of these models in our study, the technology enactment framework and the process model of computing change. This combination allows us to better understand how OGD initiatives and social structures affect each other. We use the technology enactment framework to inform the general dynamic interaction between OGD and the organization and the process model of computing change to investigate how this interaction takes place in practice.

\subsection{An institutional approach to technology, institutions, and organizations}

Based on the institutional tradition, technology enactment theory has been used to explain the relationships among institutional arrangements ${ }^{1}$, organizational forms, and information technology in government agencies (Fountain, 1995, 2001). According to this framework, organizational characteristics and institutions have an impact on how technology is selected, designed, implemented, and used in public organizations (Gil-Garcia, 2012; Hassan \& Gil-Garcia, 2008). At the same time, however, technology can affect the organizational structures and the

${ }^{1}$ According to Scott (2001), institutions are "cultural-cognitive, normative, and regulative elements that, together with associated activities and resources, provide stability and meaning to social life" (p. 48). In the e-government field, institutions are the current formal and informal rules, incentives, and constraints embedded in the government structures (Gasco, 2003). 
institutional arrangements (Hassan \& Gil-Garcia, 2008; Scott, 2001). There is, therefore, a reciprocal relation between social and organizational structures and technology.

Fountain (2001) explains that information technologies are modified by organizational and inter-organizational factors, resulting in enacted technologies, a term that refers to the perception, design, and use of the objective technologies. In addition, institutional arrangements influence organizational forms, with structural characteristics such as centralization, formalization, and communication channels, and therefore also have an indirect impact on the enacted technology. Further, the enacted technology produces (good or bad) organizational outcomes that may result in modifications of the technology itself and, in the long run, transformations of the organizational forms and even the institutional arrangements. "Thus, the technology enactment framework recognizes the complex relations between information technology and social structures, including organizational characteristics, institutional arrangements, and other external forces" (Gil-Garcia, 2012, p.44). Figure 1 below summarizes the model.

Figure 1: Technology enactment framework (Fountain, 2001)

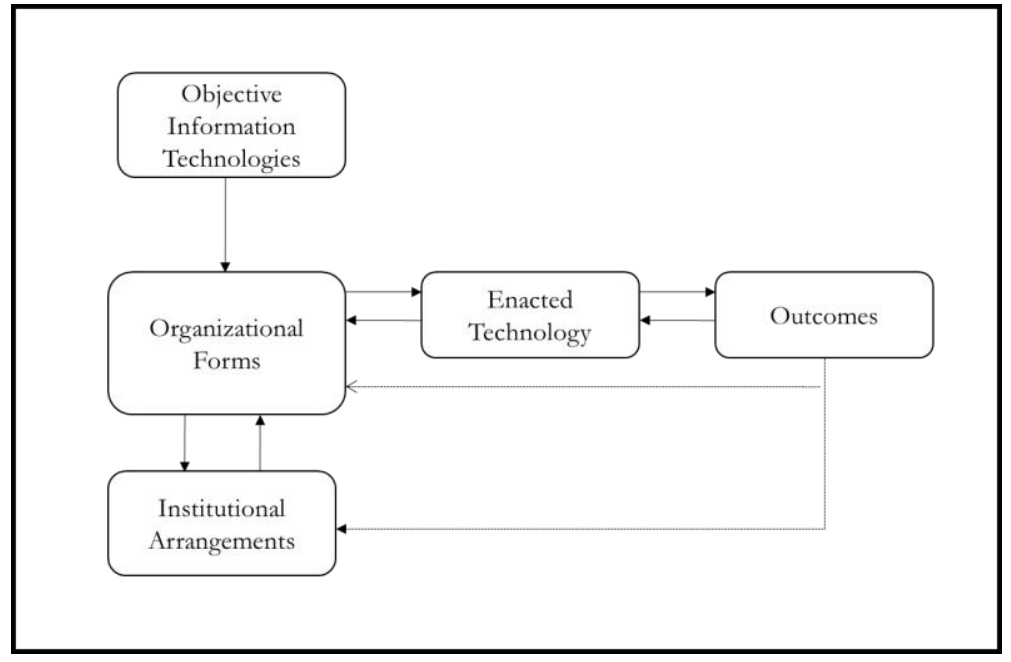

While this model is useful to analyze the influence of organizational structures and institutional arrangements on ICT implementations in the public sector (Cordella \& Iannacci, 2010), it has not been exempt from criticism. Yildiz (2007) and Schellong (2007) summarize one critique of the model in relationship to environmental factors, which are important and missing in the technology enactment framework. Cordella \& Iannacci (2010) and Gil-Garcia (2012) also acknowledge the role of contextual variables that were not included in the original framework. The latter adds this construct to his broader model for understanding electronic government success. He states, “Organizational, institutional, and contextual factors, as well as their multiple interactions, affect the way information technologies are selected, designed, implemented, and used in government organizations" (p. 54).

We therefore use the technology enactment framework as the foundation of our conceptual model to analyze open data initiatives, but follow Gil-Garcia (2012) to extend it by adding environmental conditions as a third construct to develop a more comprehensive understanding of 
the inception and implementation processes of opening government data. Similarly, we acknowlege the importance of objective technology as a concept, but we characterize it as part of the context and consequently do not have an explicit construct in the model for that variable. In fact, objective technology could be seen more as one of the initial conditions in the model and the enacted technology already accounts for some of those initial technological characteristics and features. The enacted technology could be seen as the result of the objective technology after being filtered by the organization in which is being implemented or used.

\subsection{Understanding the role of management in organizations}

The process model of computing change (Kraemer et al., 1989) is an integrative model based on the socio-technical perspective, in which any organization consists of two subsystems that are interdependent: the social and the technical. Any redesign or reorganization of the components of one subsystem necessarily has an impact on the other (Chen \& Nath, 2008). From this view, information technologies are conceived as socio-technical networks that bring together, among others, equipment, equipment vendors, information technology policies, and funding with the people who will use them (Gil-Garcia, 2012; Kling, 2000). As a result, information technologies are socially shaped or, as Kling (2000) puts it, this perspective shifts from viewing information technologies as having impacts to an appreciation that the impacts of information technologies are socially shaped.

The process model of computing change is based on research on local governments, which makes it particularly useful for our study. Kraemer et al. (1989) argue that both managerial voluntarism and environmental determinism offer partial explanations for the use of information technologies in organizations (Gil-Garcia, 2012). Thus, their model acknowledges the role of internal (organizational) and external environmental variables and, more importantly, the role of managers. Kraemer et al. (1989) state that although all environmental factors have an impact, it is not a direct relationship, but rather mediated by the actions of managers, which might also be conditioned by their management objectives and interests. Figure 2 summarizes the full model. 
Figure 2: Process model of computing change (Kraemer et al., 1989)

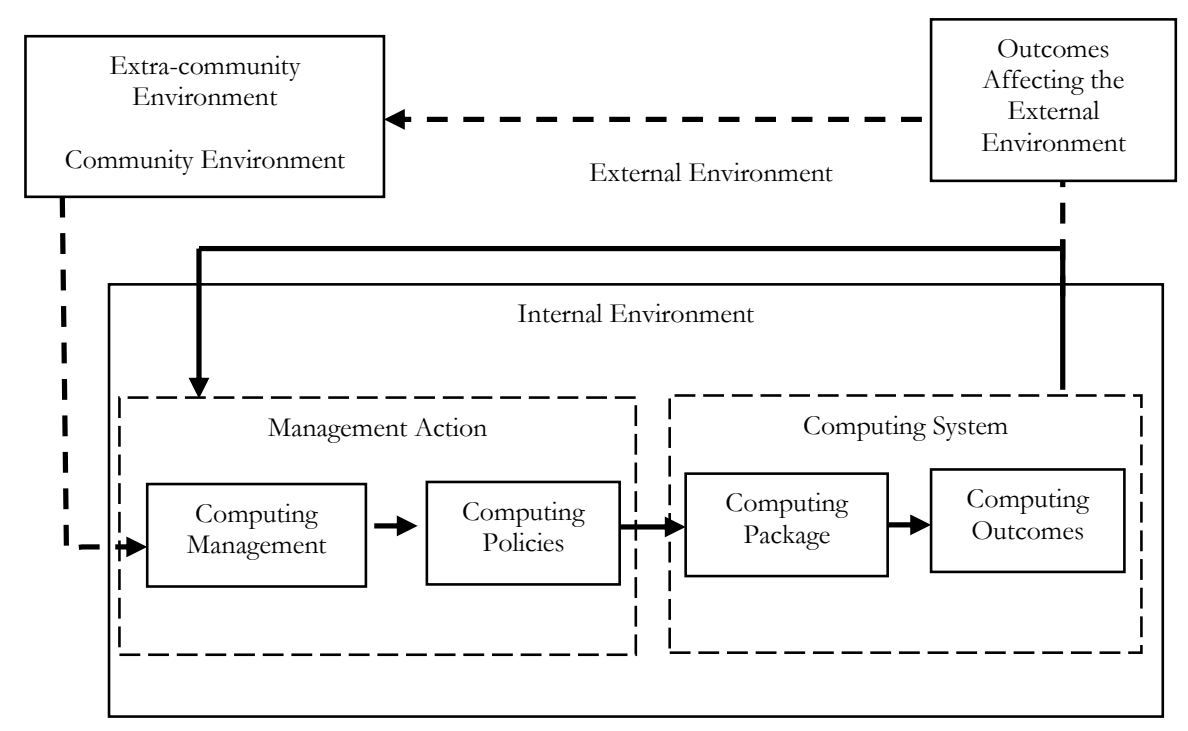

Kraemer et al. (1989) refer to the technology as the computing package and define it as "the system of people, equipment, and techniques involved with computing within an organization" (p. 53). They also use the term computing management to refer to the managers. Regarding the external environment, they differentiate between the community environment (the community that the government serves) and the extra-community environment (which comprises those factors outside the jurisdiction of the local government). Finally, "computing outcomes are the results of computing packaging operations that affect the computing system" (Kraemer et al., 1989, p. 106) and can be objective and subjective.

Building on Kraemer et al. (1989), our conceptual framework recognizes the role of managers and the influence of their actions, shaped by their interests and professional goals, but also beliefs and perceived needs (Kraemer et al., 1989; Zhang \& Feeney, 2018), on the inception, implementation, and outcomes of an open data portal.

\subsection{Enacting open data}

Knowledge of the broad interaction between organizational forms, institutional arrangements, environmental conditions, and technology is not enough to grasp the mechanisms and processes by which that interaction happens. We need a better understanding of how internal and external opportunities and constraints are altered by managers and management teams, leading to decisions that will result in an open data portal, as well as how the resulting portal and further outcomes feed back to the manager and/or management team. Our conceptual framework combines the models proposed by Fountain (2001), incorporating the additions suggested by GilGarcia (2012), and Kraemer et al. (1989) to analyze the open data initiatives of three local governments. Figure 3 shows the general framework while Figure 4 shows the detail of the construct called "organizational forms". 
Figure 3: Open data enactment model

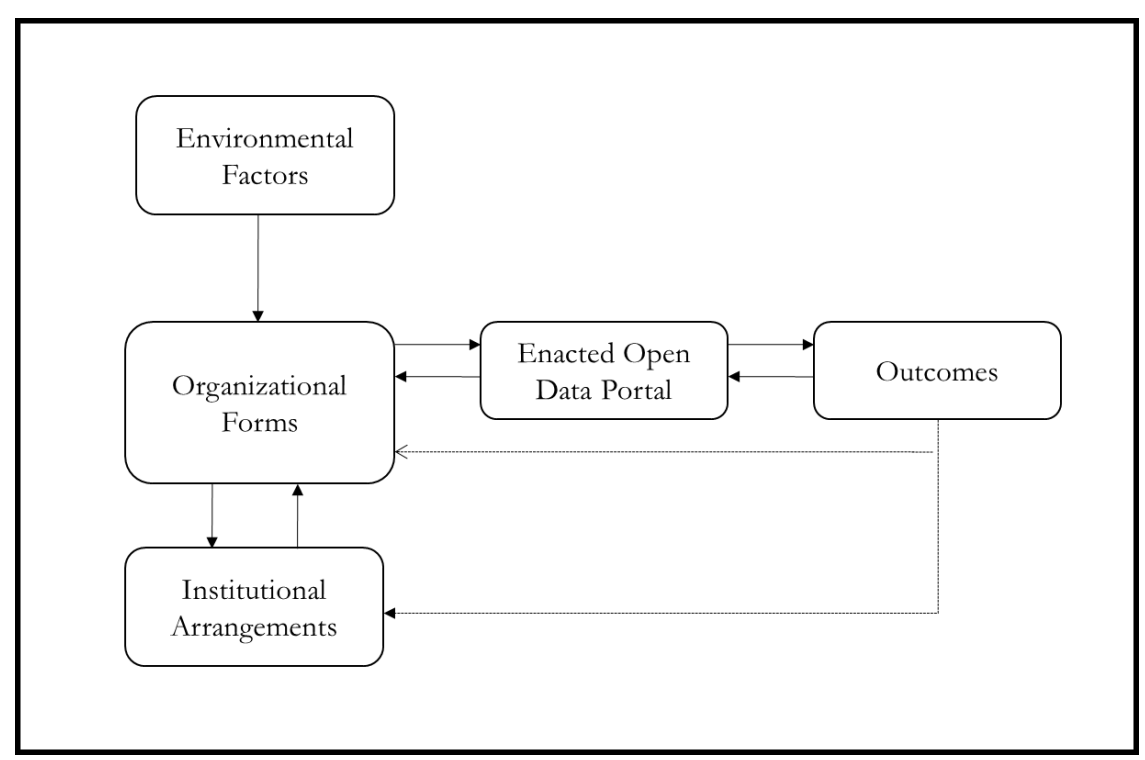

The main difference between our proposed model and previous technology enactments frameworks (including Fountain, 2001 and Gil-Garcia 2012, among others) is that we are proposing to unpack the construct organizational forms into three related but distinct variables: 1) organizational characteristics, 2) decisions, strategies, and policies, and 3) management. Organizational characteristics are related to the more enduring features of an organization such as hierarchical structure, channels of communication, size, etc. Decisions, strategies, and policies refer to the decisions made regarding the open data portal (for example, in terms of goals, strategies, and operational procedures) as well as to the processes that lead to such decisions. Finally, the variable management refers to the characteristics, interests, motivations, beliefs, and perceived needs of the individuals (public managers) and/or teams making the decisions.

Figure 4: Unpacking Organizational Forms: The Role of Management 


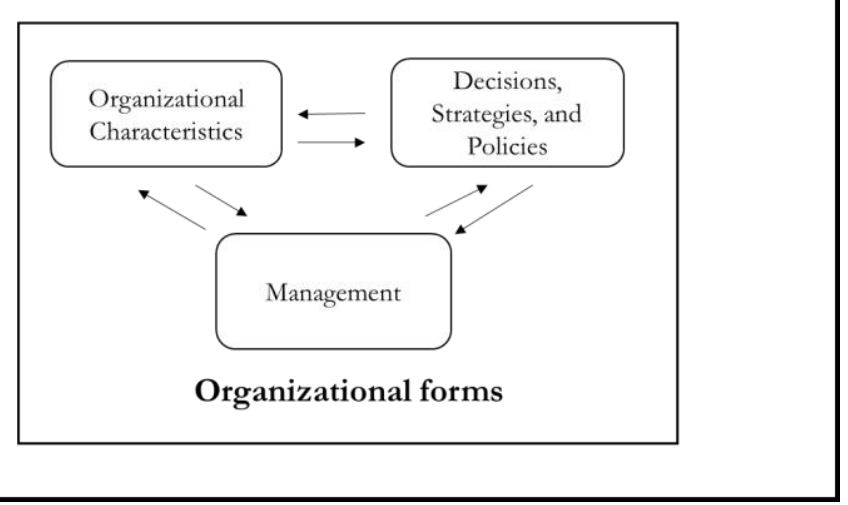

\section{Research design and methods}

The main objective of this article is to explore the bidirectional relationships between open data initiatives and organizational, institutional, and environmental factors, specifically looking at the role of management in these interactions. This approach is novel because prior open data studies have fallen short in recognizing the complexity of such relationships. Our study is therefore motivated by the following research questions: (1) what are the results of opening government data?, and (2) how do different types of factors (organizational, institutional, environmental) affect open government data initiatives? We selected the case study approach for this research, which is particularly useful to respond to questions related to why or how (Yin, 2009). In addition, case studies show how particular practices are developed in specific organizations and, therefore, help refine theory (Scapens, 1990). Qualitative case studies also allow us to study the research questions in depth while leaving room for unexpected, interesting findings that can form the basis for specific hypotheses to be tested in future research (Marshall \& Rossman, 2011; Yin, 2009). This is particularly useful when there is little existing research on the topic (Yin, 2009), as is the case here.

The cases were selected based on their relevance for this study in terms of their open government data initiatives. We therefore looked intentionally into three pioneering local governments in Spain: Gijon in the Autonomous Community of Asturias (North of Spain) and Gava and Rubi in the Autonomous Community of Catalonia (North-East of Spain). The three cities had three things in common: (1) they were not the capital of their respective provinces and Autonomous Communities, (2) they had started their open data portals long before other similarsize local governments in Spain, and (3) their approach to open data went beyond publishing the data and focused on achieving real open government by means of being more transparent and encouraging collaborative innovation. The utilization of a most similar case design held constant many otherwise confusing and irrelevant variables, allowing to infer correlation or even causality from the few variations of the cases.

The research design was chosen because it suited our research questions and enriched our understanding of the research context (Yin, 2009). Five individual semi-structured interviews were conducted with current managers involved in the deployment of the open data portal in each of the local governments of our sample (fifteen interviews in total). All of the participants were 
contacted by e-mail, provided with an overview of the research project, and asked to take part in the study. Given the past and current links of the researcher and her institution with the different local governments, research access was straightforward. Interviews lasted between one and two hours. The interviews focused on five main topics: (1) drivers of adoption of open data portals, (2) stages of development, (3) determinants and barriers, (4) organizational transformation, and (5) perceived outcomes. Interview notes were transcribed and hand-coded line-by-line using the predefined codes from the existing literature on open data (among other, Van Veentsra et al., 2010; Susha et al., 2015; Zuiderwijk \& Janssen, 2014; Sayogo et al., 2014; Veljovic et al., 2014; Parycek et al., 2014; Solar et al., 2012; Janssen et al., 2012).

\section{Analysis and results}

In this section, we use the enactment open data model to analyze the interaction between open data initiatives and organizational, institutional, and environmental factors. Open data initiatives in the public sector are complex and face important challenges that are not only related with the technology used or the quality of the data. These initiatives are affected by the capabilities of the government agencies, existing laws and regulations, and diverse economic, political, and social variables.

\subsection{The enacted open data portal}

Gijon is the second largest city by geographic size in the Autonomous Community of Asturias, although it is the most populated city in that region (around 275,000 inhabitants). In 2009, after the establishment of the World Wide Web Consortium (W3C)'s Spanish office in Gijon, the city started to heavily invest in technology in government, progressively becoming a reference for egovernment, smart cities, and open government across the rest of the country. In January 2011 Gijon launched its first open data portal in compliance with the national Law 37/2007 on reuse of information in the public sector. This portal was redesigned in 2013 to further promote the opening of information, from both a quantitative and a qualitative perspective. At the end of that year, more than 400 datasets were available. This number significantly increased during 2014 and, at the time of writing, there are 707 datasets available in multiple formats.

Gava is a smaller city in the province of Barcelona, in the Autonomous Community of Catalonia. It has around 46,500 inhabitants. The adoption of technology by the local government was not a priority for the city until 2011, when a new City Manager was hired. In 2012 a local ordinance on electronic services was passed and in 2013 the new Mayor decided to politically support the open data initiative led by the City Manager. In 2014, the open data portal "Gava Obert" ("Open Gava") was launched in cooperation with the US company Socrata. Despite its early start, the project experienced a setback when, one year later, the City Manager left the city council. It was not until October 2015, when the city hired a Coordinator of Municipal Strategic Planning, that transparency and data-driven innovation were re-introduced in the agenda. At the time of writing, Gava Obert has 167 datasets available. 
Finally, Rubi has a similar profile to Gava. It is located in the province of Barcelona, in the Autonomous Community of Catalonia. It is larger than Gava (around 75,000 inhabitants), but smaller than Gijon. The city has never been a leader in e-government but, following Gava's example, in November 2014, it launched its first open data portal, led by the Mayor and the Department of the Presidency. A few months later, the Open Data Institute in the UK shortlisted it for the Open Data Award 2015. The project has moved very slowly, due, among other reasons, to a change of government party leadership and its associated change in high-profile executive managers in 2015. At the time of writing, Rubi only has 63 datasets available.

The three open data portals follow a similar pattern, the one developed and implemented by Socrata, the company hired in all three cases. The data sets are organized according to different sectors: economic activity, population, tourism, transportation, health, and the environment (among others). Most of the data can be opened in several formats, such as XML, CVS, Excel, ORG, RDF, and PDF. The three cities offer several data visualizations on the portal. But they also go further, offering citizens and the general community to create their own visualizations and upload them on the portal. They call this functionality "Vision Ciudadana" (Citizen View) in the cases of Gava and Rubi and "Observa Gijon" (Observe Gijon) in the case of Gijon. In addition, these sections include discussion boards for citizens to comment on the data and the visualizations.

Despite their similarities, each portal has its own unique features. For example, Rubi and Gijon both provide an option for users to suggest datasets they would like to see published. The requested datasets are not immediately released, but go through a political validation process after staff confirm that the datasets are available and of public interest. Gava has a section specifically addressed to developers, which gives them access to the Socrata Open Data API. Finally, Gijon publishes the list of applications and widgets that use one or more datasets from the portal.

\subsection{Outcomes}

According to our interviewees, becoming a (more) open government was the main motivation for the cities of Gava, Rubi, and Gijon to open their data to the public. Although the three city councils had to comply with the Spanish Transparency Law, which went into effect in December 2013 and made transparency an important goal of the data opening process, transparency was more important in the cases of Gava and Rubi, while collaborative innovation and economic development were more central for Gijon. As stated earlier, Gijon had already launched its first open data portal back in January 2011 in compliance with the national Law 37/2007 on reuse of information in the public sector, a law particularly aimed at supporting private organizations' (re)use of information in order to contribute to economic growth and employment. In fact, the Department of Economic Promotion was the first agency in Gijon to release its data.

A few years later, it is difficult to assess whether these goals have been achieved. Our interviewees referred to the number of new datasets, the number of dataset views, and the number of new apps using OGD as indirect measures (outputs) to evaluate their accomplishments. In terms of numbers, Gijon's portal has the most datasets available. Given the different starting points, however, the three cities have all heavily invested in opening new data sets. For example, only in the last year, Rubi published 30 new datasets (an increase of almost 91\%), Gava added 45 
(an increase of nearly 37\%), and Gijon added 79 (an increase of about 12.6\%). In terms of views, there is no common trend and each dataset within the portal varies in its popularity. If we take the case of Rubi, police activity is the most viewed dataset. At the time of writing, it has been viewed 37,770 times. The second most viewed data set is population changes during the period 1996-2017, viewed 6,302 times. At the opposite end, we find protocol expenses for 2015, with only 120 views. In Gava, the numbers are much lower. The most viewed dataset is the directory of private companies $(3,067)$, followed by staff expenses $(2,891)$, while the least viewed is the income budget for 2013 (only eight views). While Gijon does not show the number of views, it is the only city to report the number of apps that use their datasets: 14 city applications have been developed with the OGD, all of them before 2015.

Given these numbers, our interviewees perceived that they were far from reaching their goals, although Gijon and Rubi reported improvements in the Transparency Index developed by International Transparency (Gava is not on the ranking yet): Rubi moved from 90th (72.5/100 points) to 58th (93.8/100 points) while Gijon moved from 20th (98.8/100 points) to 1st (100/100 points). Regarding reuse and innovation, the level of engagement from the developer community was perceived as low, despite the organization of multiple communication and marketing events. That said, most of our interviewees agreed on the positive impact of open data in terms of the government's public image. In the specific cases of Rubi and Gava, being two of the first cities in Spain to have open data portals put these lesser known cities on the map.

\subsection{Institutional arrangements}

Laws and regulations were the main institutional arrangement affecting the decision to launch open data portals in the three cities. In the case of Gijon, Law 37/2007 on reuse of information in the public sector was key. Although the Law only mentions "open data" once, it promotes the provision and use of information in open and machine-readable formats. It also refers to open standards and licenses. However, the most influential law in the decision to set up an open data portal in the three cases, particularly in Gava and Rubi, was the Spanish Transparency Law. Although the law went into effect in 2013, local governments had until December 2015 to comply with it. The law is focused on active transparency and that is why many local governments thought of open data portals as their main strategy for compliance. Rubi and Gava were no exception. Even Gijon, which already had an open data portal, prioritized complying with the law and created a Technical Committee on Transparency, Open Data, and Information Reuse. As a result of the open data portal, Rubi started to develop a local ordinance on electronic government and transparency, but the project was abandoned given its complexities. More successful was Gijon, which approved its Municipal Ordinance on Transparency, Access, and Reuse of Information and Good Government back in 2016. There was a clear bidirectional relationship between institutional arrangements and the open data portal in this case.

Finally, our interviewees believed that other institutions such as culture also played an important role in the results from the open data projects. Spain's culture of opacity (reflected, for example, in the fact that it was the only European country with a population of over one million people that did not have a transparency law enacted until 2013), which is particularly strong in public 
organizations, has hindered the publication of what participants deemed to be important data. According to our informants, that culture of opacity also influences citizen expectations of government, which has prevented them from being aware of their right to access public information and might explain the low number of views for many of the published datasets.

\subsection{Environmental factors}

Citizens' demand, nonprofit's pressure, competition with other local governments, isomorphism, and the political leadership of the Mayor were found to be the most influential environmental conditions for open government data. Interviewees from the three cities acknowledged that citizen demand for transparency was an important factor, although as explained before, affected by the opacity culture in Spain. One of the interviewees from Gava explained, "Citizens' pressure for transparency was key. Without this pressure, the project would not have been initiated. This project would have not been feasible six years ago".

In the particular case of Gijon, our interviewees recognized that, externally, there was a great deal of pressure coming not only from citizens, but also local organizations. A good example is the role of the Foundation Technological Center of Information and Communication (Foundation CTIC is the Spanish acronym), which hosts the Spanish office of the World Wide Web Consortium (W3C). Foundation CTIC had already worked with several regional governments, such as Galicia and the Basque Country, as well as with other local governments in Spain, such as Barcelona. Given this knowledge and the expertise, and the fact that the Foundation is based in Gijon, they convinced the city council to start an open data portal. The first conversations about the portal took place in 2010, but a change of government party leadership in 2011 forced the Foundation to start over with the new council team. Ultimately though, Foundation CTIC became an active partner in the initiative and supported the city council during the first years of the portal's operation. Leadership from their city councils was also important for Gava and Rubi in the development of their open data portals.

Knowing what other cities, mainly within the United States, had accomplished was also key to how these three cities made certain technical decisions, such as who the technological partner was going to be. Within Spain, Rubi saw Gava as a model to follow, and several decisions were quite mimetic (institutional isomorphism). Finally, political conditions also had an influence on the enacted technology in the three cases, but in different ways. Our interviews showed that in Gava and Rubi, the local elections of 2015 resulted in a change of Mayor that hindered the implementation process, challenging its sustainability. On the contrary, the election results in Gijon were beneficial for the project since the same Mayor remained in office, thereby maintaining transparency and open data as a priority in the political agenda and enhancing sustained further development of the portal.

\subsection{Organizational forms}

In the three case studies, organizational factors were revealed to be particularly important during the implementation stage. In the three cities, the lack of implementation guidelines was one of the 
most important factors. In the cases of Gava and Rubi, there was never a plan to follow, clear goals, and tools. As one of our interviewees put it, "We did not have a defined policy; we were only being reactive". Certain characteristics of the project also hindered the implementation process. Setting up the portal required the city to gather all the data in one database in a standardized format. Most of the data, however, was in Excel files (or even in PDFs) and was not standardized. Further, the data was disorganized and at times the departments knew they had it, but did not know where.

However, as stated by our interviewees, the bureaucratic characteristics and culture of government organizations had the greatest negative influence on implementation. There was reticence to share the data, which had been independently collected by different departments within a specific city council; there was also resistance to working together and to sharing common work methods and tools. "The departments did not want to give us the data that we had decided to publish", said one of our interviewees. "The data sets belong to the departments but we have a culture based on a lack of collaboration and information sharing", added another one. Our informants cited fear as one reason for this reluctance: "The staff thought we were controlling them; they did not realize it was not about control but about quality and transparency"; "We wanted to change a paper-based organization into an organization 2.0, but technology is scary". But there was also fear about showing what was being done and placing it under public scrutiny: "We were afraid of telling what we were doing. For example, if we show how much we collect in property taxes, those living next to the beach will complain because they pay more. But, then, we will have to explain them why! We were afraid of addressing citizens' complaints".

In addition, there was a low level of internal understanding of what open data was and what its positive effects could be. The predominant culture in the city government up to that point was document-based, not data-based: "The concept of open data has nothing to do with having a document repository, but with having sets of reusable data. This is difficult to understand". In all three cases there was a lack of communication and training, which was considered key by our interviewees: "If we do not understand internally what open data is about, how are citizens going to understand?" In the specific case of Gijon, given their goals of innovation and economic growth, interviewees also referred to an organizational culture that was not entrepreneurial: "We are not realizing the opportunities of a digital economy; we do not understand data is free raw material".

Interestingly enough, one of the goals of the portals was to inspire a change of culture. For most of the interviewees, however, launching the open data portals did not have an organizational impact. It did not lead to more transparent internal processes or a more open and cooperative culture. What it did provide was valuable information about the organization to the people in charge of the initiative: "We did not realize, but we ended up with a fantastic diagnosis of the organization; we learnt how we were doing and, therefore, how we could improve". Some of our interviewees stated that the culture would eventually change, but the process was going to be slow given the rooted lack of transparency that have characterized local public organizations for a very long time.

None of our interviewees mentioned funding as an issue. The cost of setting up the portal was relatively low, generally less than 20,000 Euros. Despite this observation, our interviewees from 
Gijon explained that while the technological tool was cheap, it did not quite meet their needs: "The platform was very limited; we needed to adapt it to our context and that took a lot of time". They stated it was a good tool to start from scratch, which made it a good solution for Gava and Rubi, but not for Gijon, which had developed its first open data portal back in 2007. Thus, the size and scope of the project mattered and determined the level of resources needed beyond just money, including specialized staff and/or external consultants.

\subsection{The role of management}

The general framework depicted in Figure 3 is not enough to understand the inception, implementation, and success of open data portals in public organizations. The model shows the general interactions between the different constructs but does not offer additional information about the specific mechanisms and processes, influenced by the action of managers, by which those relationships happen. In this section, we use Figure 4 to analyze these relationships in detail, highlighting the role of management (both managers and management teams) and their decisions.

Although Figure 4 refers to "management" generally, in our three cases this term included more than the City Manager, reflecting the existence of a dual power structure, political and administrative, that prevails in Spanish cities. Each case was different: in Gava, the management included the Mayor, the City Manager, and the Chief of Staff; in Rubi, it included the Mayor, the Director of the Presidency, and the Special Informative Committee on Transparency and Good Government; and finally, in Gijon it included the Chief of the Department of Planning and Modernization, the Town Councilman of Public Administration and Finance, and the Technical Committee on Transparency, Open Data, and Information Reuse ${ }^{2}$. Several interactions took place among the different individuals and the committees before any decisions were actually made. Therefore, the variable management in many cases represent a variety of individuals and collegiate groups that make decisions together following certain rules.

In the cases of Gava and Rubi, the interests and management objectives of the two senior public managers (the City Manager in Gava and the Director of the Presidency in Rubi) were key in the decision to launch the open data portal, once they knew they had to comply with the new Spanish Transparency Law. Both of them were very active in promoting the use of technology by local governments and in making them more transparent. However, once they had made their decision, they had to convince their Mayors.

In the case of Gava, a new Mayor arrived in early 2014 and she took on the portal as a flagship project for her administration. The Mayor completely trusted the City Manager and granted him the leading role in the project. However, there was a history of failed projects in the city and

2 The management team in Gijon has changed over time. The Chief of the Department of Planning and Modernization, the Town Councilman of Public Administration and Finance, and the Technical Committee on Transparency, Open Data, and Information Reuse were part of the management when the interviews were conducted. 
having the Mayor on board was not enough: "I had to look for an internal ally, and that was the Chief of Staff. He was interested in 'new politics' and he firmly believed in transparency". The City Manager took personal responsibility for the risk of the project and became a champion of it: "I only focused on the benefits, on the positive". His first decision was to explore what other big cities were doing with their data. He started at the national level, but soon realized those open data portals had a lot of limitations. He then turned to Chicago and New York, became aware of Socrata and their work, and decided to partner with them.

During approximately three months, online meetings with the different actors involved in the project took place once a week, although, in practice, it was Gava's City Manager who was in charge and making the most important decisions. He elaborated an open data plan, following San Francisco's, that established what to open, how, and when. He personally requested that the departments release the data. Internally, no one was aware of the project: "Only a few people knew about the project; politically, only the Mayor. If many people had been aware of it, it would have raised a lot of concerns and it would have led to greater debate, which would have probably delayed implementation". However, for some of our interviewees, this was not a good strategy because city agencies were never fully informed and convinced of the benefits of opening data. This became even worse when the City Manager accepted a new job in November 2014. The project was so personal that, once he left, it was put on hold: “...the Mayor is very busy and we do not have a City Manager anymore. The rest of the staff does not believe in the project and there is a huge gap between the top of the organization and the departments, which do not understand what open data is nor how useful it can be". Only in October 2015, after all of our interviews were over, did the city hire a Coordinator of Municipal Strategic Planning who, slowly, reactivated the project.

In Rubi, the Director of the Presidency shared a passion for transparency and technology with Gava's City Manager and, given their personal and professional relationship, was aware of his steps to launch an open data portal. He decided to do the same in Rubi and shared his goal with the Mayor, who quickly was onboard. They informed the Special Informative Committee on Transparency and Good Government, which had to approve the project and decided to appoint the Director of the Presidency as the person in charge. The Special Informative Committee on Transparency and Good Government also decided on the technical proposal, which included a partnership with Socrata. However, according to our interviewees, the leader of the project was the Director of the Presidency: "He clearly led the project, and the team worked very well together under his leadership". From this, it is clear that understanding the specific role of managers can provide insights on how isomorphism takes place and what are some of the mechanisms of this mimetic behavior.

Despite the leadership roles that both the City Manager of Gava and the Director of the Presidency of Rubi had, they led their projects in different ways. As previously described, the former became the core of the initiative: he made the decisions and executed them. He did not upload the datasets himself, but he was personally participating in every step taken. The latter had a more collaborative leadership style: he oversaw the project and led it technically, but heavily relied on his team for technological issues and decisions and cooperated with the political 
guidelines established by the Special Informative Committee on Transparency and Good Government.

Given the larger involvement of the organization as a whole, there was also room for staff to raise more concerns and difficulties in Gava. As a result, the implementation process also included developing a manual and recording videos addressed to the different departments. They also had plans for future staff training given the lack of awareness and understanding of open data, but also to address the misinterpretations about its implications: "Our staff did not know anything about open data"; "Open data is hard to understand; reuse of information is hard to understand"; "People are concerned because they think open data will increase their workloads"; "We do not have an open data culture". These were just a few of the concerns expressed by multiple interviewees. In addition, the City Observatory, which was part of the Department of Studies and Statistics, supported the management team in disseminating information about the initiative externally and organized several activities aimed at engaging citizens in reading and using the open data. In sum, there was greater interest in making the project visible both internally and externally.

The local elections held in May 2015 resulted in a new Mayor in Rubi and, consequently, in the departure of the Director of the Presidency a few months after, which froze the project for a period of time. Thus, from 2015 to 2016 only ten new datasets were added to the portal. Lately, however, there seems to be more activity (from 2016 to the time of writing, the number of datasets has doubled) and the new Mayor has publicly committed to transparency and open government. It is important to emphasize that the organizational capabilities and institutional arrangements during the whole period were basically the same. The main difference was the managers and how committed and interested they were about transparency in general and the open data portal in particular.

In the case of Gijon, the management objectives and interests of a specific public manager were not as relevant as in the two previous cases. Instead, back in 2010, the Foundation CTIC conveyed the importance of open data and reuse of information to the city council. However, the local elections held in 2011 forced a change of government and a new Mayor from a different political party took office. Once more, Foundation CTIC stressed the need for open data and reuse of information; the new city council, which wanted to comply with the national Law 37/2007 on reuse of information in the public sector, agreed. The council therefore set up a multidisciplinary group, which included Foundation CTIC and was led by the Department of Economic Promotion, to design and implement the portal ${ }^{3}$.

In January 2011 Gijon launched its first open data portal. The partnership with Foundation CTIC proved highly beneficial. This organization had already served other city councils and worked hard to identify new datasets, convince staff about the benefits of open data, and engage with citizens and civic organizations. After two years, in 2013, Gijon launched a new open data

${ }^{3}$ However, our interviewees indicated that, informally, Foundation CTIC played a key leadership role. 
portal with more than 500 datasets and two hackathons were organized to promote its use. At the end of that year, the Spanish Transparency Law was passed and the city decided to start a transparency portal to complement the open data one. Transparency and open data use and reuse were such important priorities that, in 2014, the Technical Committee on Transparency, Open Data, and Information Reuse was created and became part of the management team. It was in charge of making decisions about what to open, although the Chief of the Department of Planning and Modernization had general responsibility for both the open data and the transparency portal. For example, in 2015 he decided to use Socrata (just like the other two cities in our case studies) to improve the portal and add new functions 4 . As in Rubi, his leadership style was collaborative: he had been given a lot of autonomy by the Town Councilman of Public Administration and Finance, but also had a strong and knowledgeable technological team, which made operational decisions.

According to our interviewees, in Gijon there was an explicit will to change the culture of the organization, to make it more collaborative and open, and also to establish common work procedures. However, there was great resistance to change and both formal and informal initiatives were put in place to overcome it, such as meetings, talks, workshops, and training. The Technical Committee on Transparency, Open Data, and Information Reuse was particularly active in this respect. The local elections of May 2015, held after our interviews took place, did not result in a change of government. Thus, the same management team is still making the decisions about open data today, which might explain the project's sustainability over time and its successes in terms of outputs (see section on expected outcomes above). Considering the three cases together, it seems clear that managers and their decisions matter, affecting the final outcomes in terms of the success and sustainability of open data portals.

\section{Conclusions}

The main objective of this article was to understand the interplay between social and organizational structures and some characteristics of open government data initiatives (including their inception, implementation, and results). Our findings lead us to draw three general conclusions. First, we corroborated most of the relationships proposed by previous studies using the technology enactment framework and some extensions (Kraemer et al., 1989; Fountain, 2001; Hassan \& Gil-Garcia, 2008; Cordella \& Iannacci, 2010; Gil-Garcia, 2012). We confirmed that organizational forms (structures and processes) affect how open data portals are designed, implemented, and used. Specifically, clear goals and implementation guidelines, the bureaucratic attributes and organizational culture of the local governments, characterized by a lack of

\footnotetext{
${ }^{4}$ Given Gijon's previous achievements, both in terms of technology and data, the relationship with Socrata was not as smooth as in the cases of Rubi and Gava, which were building their portals from scratch. Gijon already had an infrastructure that was working and had additional needs that made adaptation of the tool more difficult than in the other two city councils.
} 
transparency and of understanding of open data, and the size and scope of the project proved particularly important in the three cases.

In addition, institutional and contextual factors shape organizational characteristics and, in doing so, affect the final open data portal results (Kraemer et al., 1989; Fountain, 2001; Gil-Garcia, 2012). In fact, the Spanish Transparency Law, in effect since 2013, was the most influential regulation in the decision to set up an open data portal in the three cases. Even in Gijon, which had already launched an open data portal back in 2007, the new law triggered the creation of the Technical Committee on Transparency, Open Data, and Information Reuse, (re)emphasizing the priorities of the local government: transparency and open government. Interestingly enough, in the cases of Rubi and Gijon, we also found a direct relationship between institutional arrangements and the enacted open data portal: the existence of the portal and the need to promote its use resulted in regulatory processes that were only finally successful in Gijon (the Municipal Ordinance on Transparency, Access, and Reuse of Information and Good Government was passed in back in 2016). We argue that more research is needed in this regard.

Second, analyzing the role of management is very important because it is a way to understand some of the mechanisms by which organizational-level variables affect each other. A new law does not automatically influence organizational structures and processes. The content is interpreted by one or more managers, who react to it and make decisions that affect one or more variables in the organization and the open data portal. The relationships between organizational-level variables we document in this study are not always, in fact, almost never, direct. They are mediated by the role of managers or management teams and their decisions and strategies, which are influenced by their individual and collective interests, beliefs, expectations, styles, and objectives (Kraemer et al., 1989; Zhang \& Feeney, 2018). Management's perceptions and decisions are also affected and constrained by organizational, institutional, and contextual variables (Gil-Garcia, 2012). Our three cases show that the management team influenced the relationships in different ways, but consistently had some impact. In recognizing the action of management, our study proposes one way to include them in an approach that has been mainly used at the organizational level, confirming that organizations, in general, and technological initiatives (such as launching an open data portal), in particular, are shaped by management action (be it an individual manager, a council, or a management team).

Actually, in analyzing the role of management, our study also contributes to the understanding of this concept. Our case studies show that local governments are complex organizations, which reflect a (often unbalanced) dual power structure, both political and administrative. Decisions are, then, the result of the interactions among different individuals and collegiate groups, who have different levels of power, according to the organization's formal rules and informal arrangements. Thus, the concept of management here is closer to the notion of corporate governance and it can embrace different configurations. Further, our results prove that those actors with excessive power may jeopardize the project, for instance when they leave the organization, as the cases of Rubi and Gijon show. More research is needed in terms of the differentiated effects of management on the characteristics of the open data initiatives, depending of what type of management/governance structure a local government has. For instance, it would be interesting to understand if a local 
government with a strong mayor and a council is more successful than a local government with a professional manager and a weak council.

Finally, it seems that organizational forms, institutional arrangements, and environmental conditions may be affected by the enacted technology, also mediated by the action of managers. However, our study did not find enough evidence to fully support this statement. Although our interviewees explicitly recognized that setting up an open government data portal was not only about promoting transparency and innovation, but also about encouraging a more open and collaborative internal culture, none of the portals that were analyzed resulted in a real organizational transformation, particularly in terms of culture (Zuiderwijk \& Janssen, 2014; Van Veenstra \& Van Den Broek, 2013; Janssen et al., 2012). Further, despite acknowledging the potential contribution of open data portals in general, it does not seem that having an open data portal was making a difference, by itself, in overcoming the culture of opacity within Spanish society and its government organizations. Thus, our study only shows that these relationships may exist, but further research, taking for example into account the slow nature of cultural adaptation by lagging "cultural change" by a few years, is needed in this direction.

\section{References}

Barry, E., \& Bannister, F. (2014). Barriers to open data release: A view from the top. Information Polity, 19(1-2), 129-152.

Chen, L. \& Nath, R. (2008). A socio-technical perspective of mobile work. Information Knowledge Systems Management, 7(1-2), 41-60.

Chris, M. (2014). Barriers to the open data government agenda: Taking a multi-level perspective. Policy \& Internet, 6(3), 217-240.

Conradie, P. \& Choenni, S. (2014). On the barriers for local government releasing open data. Government Information Quarterly, 31(S1), S10-S17.

Cordella, A. \& Iannacci, F. (2010). Information systems in the public sector: The e-government enactment framework. Journal of Strategic Information Systems, 19(1), 52-66.

Fountain, J. (2001). Building the virtual state: Information technology and institutional change. The Brookings Institution.

Fountain, J. (1995). Enacting technology: An institutional perspective. John F. Kennedy School of Government Harvard University.

Gasco, M. (2003). New technologies and institutional change in public administration. Social Science Computer Review, 21(1), 6-14.

Gil-Garcia, J. R. (2012). Enacting electronic government success: An integrative study of government-wide websites, organizational capabilities and institutions. Springer.

Hassan, S. \& Gil-Garcia, J. R. (2008). Institutional theory and e-government research. In GD Garson \& M. Khosrow-Pour (Eds.). Handbook of research on public information technology. Idea Group Inc. 
Hosain, M. A., Dwivedi, Y. \& Rana, N. P. (2016). State-of-the-art in open data research: Insights from existing literature and a research agenda, Journal of Organizational Computing and Electronic Commerce, 26(1-2), $14-40$.

Huijboom, N. \& Van den Broek, T. (2011). Open data: An International comparison of strategies. European Journal of ePractice, 12(1), 1-13.

Janssen, M., Charalabidis, Y. \& Zuiderwijk, A. (2012). Benefits, adoption barriers and myths of open data and open government. Information Systems Management, 29(4), 258-268.

Khayyat, M., \& Bannister, F. (2015). Open data licensing: More than meets the eye. Information Polity: The International Journal of Government \& Democracy in the Information Age, 20(4), 231-252.

Kraemer, K. L., King, J. L., Dunkle, D. E., \& Lane, J. P. (1989). Managing information systems. Change and control in organizational computing. Jossey-Bass.

Lyon, F., Gyateng, T., Pritchard, D., Vaze, P., Vickers, I., \& Webb, N. (2015). Opening access to administrative data for evaluating public services: The case of the Justice Data Lab. Evaluation, 21(2), 232-247.

Marshall, C., \& Rossman, G. B. (2011). Designing Qualitative Research. SAGE Publications.

Meijer, R., Conradie, P. \& Choenni, S. (2014). Reconciling contradictions of open data regarding transparency, privacy, security and trust. Journal of Theoretical and Applied Electronic Commerce Research, 9(3), 32-44.

Nye, J. (2002). Information technology and democratic governance. In R.A. Goldwin (Ed.). Governance.com: Democracy in the information age. Brookings Institution Press, pp. 1-16.

Orlikowski, W. \& Iacono, S. (2001). Research commentary: Desperately seeking the "IT" in IT research - A call to theorizing the IT artifact. Information Systems Research, 12(2), 121-134.

Parycek, P., Höchtl, J. \& Ginner, M. (2014). Open government data implementation evaluation. Journal of Theoretical and Applied Electronic Commerce Research, 9(2), 80-99.

Sayogo, D. S., Pardo, T. \& Cook, M. (2014). A framework for benchmarking open government data efforts. Paper presented at the $47^{\text {th }}$ Hawaii International Conference on System Sciences (HICSS). Waikoloa, HI, January $6^{\text {th_-9th, } 2016 .}$

Scapens, R. W. (1990). Researching management accounting practice: The role of case study methods. The British Accounting Review, 22(3), 259-281.

Schellong, A. (2007). Extending the technology enactment framework. PNG working paper no. PNG07-003. John F. Kennedy School of Government - Harvard University.

Scott, W.R. (2001). Institutions and organizations (2nd ed.). Sage.

Scrolini, F. (2014). Open cities: The case of Montevideo. Washington DEC: Open Data Research Network - Web Foundation.

Solar, M., Concha, G. \& Meijueiro, L. (2012). A model to assess open government data in public agencies. Paper presented at the IFIP EGOV Conference 2012. Kristiansand, September $3^{\text {rd }}-6^{\text {th }}, 2012$.

Susha, I., Zuiderwijk, A., Janssen, M. \& Grönlund, Å. (2015). Benchmarks for evaluating the progress of open data adoption: Usage, limitations and lessons learned. Social Science Computer Review, 33(5), 613-630. 
Van Veenstra, A. F. \& Van Den Broek, T. A. (2013). Opening moves - Drivers, enablers, and barriers of open data in a semi-public organization. Paper presented at the IFIP EGOV Conference 2013. Koblenz, September $16^{\text {th }}-19^{\text {th }}$.

Van Veenstra, A. F., Janssen, M., \& Tan, Y.-H. (2010). Towards and understanding of e-government induced change - Drawing on organization and structuration theories. Paper presented at the IFIP EGOV Conference 2010. Lausanne, August 29th-September 2nd, 2010.

Veljovic, N., Bogdanovic-Dinic, S. \& Stoimenov, L. (2014). Benchmarking open government: An open data perspective. Government Information Quarterly, 31(2): 278-290.

Wan, H-J \& Lo, J. (2016). Adoption of open government data among government agencies. Government Information Quarterly, 33(1), 80-88.

Wirtz, B. W., Piehler, R., Thomas, M.-J., \& Daiser, P. (2016). Resistance of public personnel to open government. Public Management Review, 18(9), 1335-1364.

Yang, T.-M., \& Wu, Y.-J. (2016). Examining the socio-technical determinants influencing government agencies' open data publication: A study in Taiwan. Government Information Quarterly, 33(3), 378-392.

Yin, R. (2009). Case study research. Design and methods. Thousand Oaks, CA: Sage Publications.

Yildiz, M. (2007). E-government research: Reviewing the literature, limitations, and ways forward. Government Information Quarterly, 24(3), 646-665.

Zhang, F. \& Feeney, M. (2018). Managerial ambivalence and electronic civic engagement: The role of public manager beliefs and perceived needs. Public Administration Review, 78(5), 58-70.

Zuiderwijk, A. \& Janssen, M. (2014). Open data policies, their implementation and impact: A framework for comparison. Government Information Quarterly, 31(1), 17-29.

Zuiderwijk, A., Gascó, M., Paycek, P. \& Janssen, M. (2014a). Special issue on transparency and open data policies: Guest editors' introduction. Journal of Theoretical and Applied Electronic Commerce Research, 9(3), I-IX.

Zuiderwijk, A., Helbig, N., Gil-Garcia, J. R. \& Janssen, M. (2014b). Guest editors' Introduction. Innovation through open data: A review of the state-of-the-art and an emerging research agenda. Journal of Theoretical and Applied Electronic Commerce Research, 9(2), I-XIII.

Zuiderwijk, A., Janssen, M., Choenni, S., Meijer, R., \& Alibaks, R. S. (2012). Socio-technical impediments of open data. Electronic Journal of Electronic Government, 10(2), 156-172. 


\section{About the Authors}

\section{Mila Gascó-Hernández}

Mila Gascó-Hernández is a Research Associate Professor of Public Administration and Policy and the Associate Research Director of the Center for Technology in Government, University at Albany, State University of New York. Her research interests include electronic and open government, e-governance, public sector innovation, smart cities, and public policy evaluation.

\section{J. Ramon Gil-Garcia}

J. Ramon Gil-Garcia is an Associate Professor of Public Administration and Policy and the Research Director of the Center for Technology in Government, University at Albany, State University of New York. His research interests include collaborative digital government, smart cities and smart governments, adoption and implementation of emergent technologies, digital divide policies, and multi-method research approaches. 